\title{
Study of the Naturally Occurring Radionuclide Concentrations and the Estimation of Dose Rates for the Samples Collected from the St. Martin's Island, Chittagong, Bangladesh.
}

\author{
M. H. Kabir ${ }^{1}$, M.M.H. Miah ${ }^{* 1}$, M.M. Rahman ${ }^{1}$, M. Kamal', M.T. Chowdhury ${ }^{2}$ \\ ${ }^{1}$ Department of Physics, University of Chittagong, Chittagong-4331, Bangladesh \\ ${ }^{2}$ Atomic Energy Centre, Chittagong, Bangladesh Atomic Energy Commission(BAEC) \\ Email: kabircu303@gmail.com, mhmiah_85@yahoo.com
}

\begin{abstract}
The activity concentrations of ${ }^{238} \mathrm{U},{ }^{232} \mathrm{Th}$ and ${ }^{40} \mathrm{~K}$ radionuclides have been determined for Sediment, Fish and Coral Samples collected from the St. Martin's Island, Chittagong, Bangladesh. A total of 7 Samples ( 4 sediments, 2 fishes and 1 coral) from 3 different kinds were analyzed by using a High Purity Germanium (HPGe) detector of relative efficiency of $38 \%$. For sediment samples, the mean activity concentrations of ${ }^{238} \mathrm{U},{ }^{232} \mathrm{Th}$ and ${ }^{40} \mathrm{~K}$ have been found $17.243 \pm 2.14,25.207 \pm 2.302$ and $460.802 \pm 50.957 \mathrm{~Bq} / \mathrm{Kg}$, respectively. The mean activity concentrations of fish samples for the corresponding radionuclide were $10.86 \pm 16.615,10.555 \pm 13.51$ and $364.92 \pm 361.345 \mathrm{~Bq} / \mathrm{Kg}$ respectively. Also for coral sample, the mean activity concentrations for the corresponding radionuclide were13.06 $\pm 2.1,16.57 \pm 2.65$ and $84.96 \pm 43.29 \mathrm{~Bq} / \mathrm{kg}$, respectively. The radionuclide ${ }^{137} \mathrm{Cs}$ has not been detected in any of the samples. For sediment samples, the mean radiological hazard parameter values of outdoor absorbed dose rate, indoor absorbed dose rate, external radiation hazard, internal radiation hazard, annual effective dose equivalent, radium equivalent activity and representative level index were $43.863 \pm 2.877,52.636 \pm 3.452 \mathrm{nGy}^{-1} \mathrm{~h}^{-1}, 0.239 \pm 0.015,0.286 \pm 0.018,53.793 \pm 3.525 \mu \mathrm{Svy}^{-1}$, $88.695 \pm 5.672 \mathrm{~Bq} / \mathrm{kg}$, and $0.673 \pm .04375$ respectively. For fish samples, the mean values of the corresponding radiological indices were $27.368 \pm 19.606, \quad 32.841 \pm 23.52 \mathrm{nGy} \cdot \mathrm{h}^{-1}, \quad 0.146 \pm 0.103$, $0.175 \pm 0.129,33.563 \pm 24.227 \mathrm{LSvy}^{-1}, 54.052 \pm 38.446 \mathrm{~Bq} / \mathrm{kg}$, and $0.421 \pm 0.302$, respectively. For the case of coral sample, the values of the corresponding radiological indices were $20.183 \pm 7.36,24.219 \pm 8.832$ nGy.h ${ }^{-1}, 0.117 \pm 0.014, \quad 0.152 \pm 0.017, \quad 24.752 \pm 9.02 \quad \mu \mathrm{Svy}^{-1}, \quad 43.29 \pm 5.466 \quad \mathrm{~Bq} / \mathrm{kg}, \quad$ and $0.309 \pm 0.041$ respectively. The obtained results of this study show that most of the sample's values are lower and the remaining are higher than the World average values. The mean representative index value is less than unity which confirms that the St. Martin area is safe for the inhabitants and the tourists. The results will be used as a baseline data for further researchers.
\end{abstract}

Keywords: Activity concentration, hazard parameters, effective dose, absorbed dose.

\section{Introduction}

Saint Martin's Island is the only coral island in Bangladesh. It is situated in the north-eastern part of the Bay of Bengal at a distance of about $9 \mathrm{~km}$ from the Cox's Bazar-Teknaf peninsula tip of Bangladesh. Its size is about $8 \mathrm{~km}^{2(1)}$. The population is about 3,700 and most of them are fishermen ${ }^{(2)}$. It is an important tourist place in Bangladesh. Every day hundreds of people visit this island.

The present research was aimed to carry out the radioactivity levels associated with sediment and other's Biota samples collected from the Saint Martin's Island to assess the radiological hazards to the tourists as well as the population nearby the Island. The concentrations of radionuclide of the samples under study were done by using a high resolution gamma spectrometry of High Purity Germanium detector (HPGe) at the Atomic Energy Centre, Chittagong, Bangladesh Atomic Energy Commission, Chittagong, Bangladesh.

Since the people of the country are not conscious about the radiation contamination and its effect on human body. In consideration of all perspectives, it is needed to find the distribution of various radionuclides present in different environmental samples. It is also necessary to explore and protect the different factors that influence the uptake of these radionuclides from environment to human food chain.

A previous work was carried out only on soil samples ${ }^{(3)}$ of the same area. In the present study sediments, 
fishes and coral samples were collected for measuring the naturally occurring radioactivity and radiological hazard parameters from St. Martin's Island. As St. Martin's is a tourist place where tourists are gathered from home and abroad, it is necessary to check whether the area is safe or not for the tourists as well as for the inhabitants who are living nearby. In addition to this, it is important to create a public awareness about the radiation hazards to the studied place.

The present work was also initiated to assess the radiological hazards for St. Martin's Island, with the ultimate aim of establishing a baseline data for the concentrations of radionuclides in the island environment.

\section{$2 \quad$ Materials and Methods}

\section{$2.1 \quad$ Study Area}

For determining the radioactivity levels of naturally occurring and anthropogenic radionuclides and for finding the radiological dose rates in the sediment and other's Biota of the St. Martin's Island, a total number of 7 samples were collected from the place. Among 7 samples 4 were Sediment samples, 2 were fish samples, 1 was coral sample. The geographical location of all sediment's sampling points was recorded by using GPS of model GPS Map 76CSx, GARMIN, and other samples were taken randomly. A map of Bangladesh, location of St. Martin Island and the sampling locations in the island is shown in Figure 1.
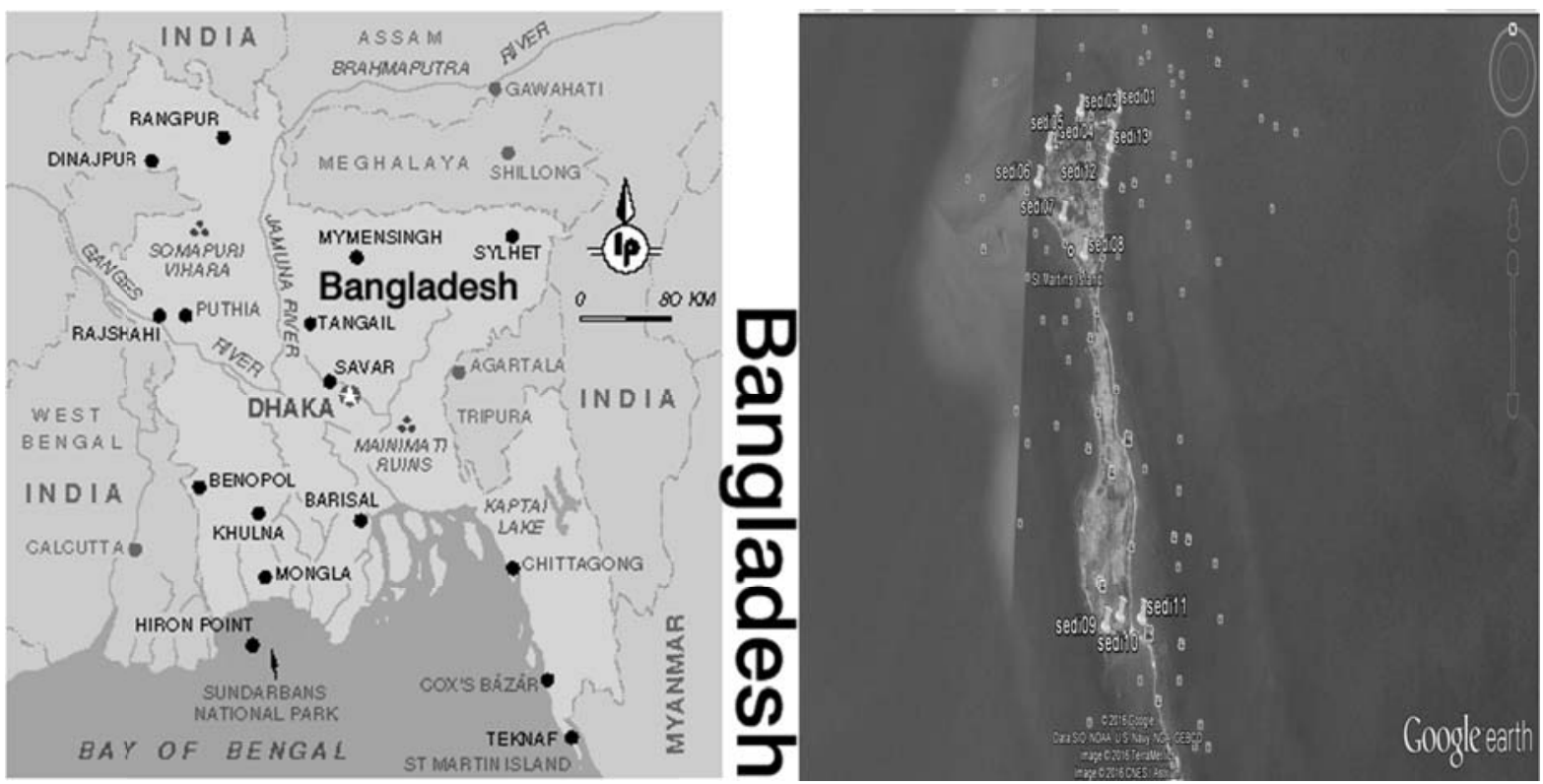

Figure 1: A map of Bangladesh with the location of St. Martin and the sampling locations for the same area.

\subsection{Sample Collection}

All the samples were collected using a cylindrical plastic container within a day on 17.10 .15 in order to avoid the atmospheric variability and the outdoor radiation exposure rates of the individuall sampling points were recorded by using a $\beta-\gamma$ survey meter (Model-3 survey meter \# 80162, LUDLUM 44-9). Each of the collected samples was stored into a sealed plastic bag individually and marked with sample identification number.

\subsection{Sample Preparation}

Each of the samples was kept under the direct sunlight for several days to evaporate the water contents. Then the samples were dried in an electric oven at temperature of $105^{\circ} \mathrm{C}$ available at BAEC,Chittagong, 
Bangladesh.For making small grain size each of the samples was ground with agitate mortar and pestle and sieved by using $0.395 \mathrm{~mm}$ diameter mesh size. The samples weight was taken by an electric digital balance and the range of samples weight were between (156-160gm) for sediment, for fishes(16-22gm) and for coral $156 \mathrm{gm}$. The final weighted samples were kept for 4 weeks in order to be equilibrium. The size of the studied sample container was of the same size as the reference sample container.

\subsection{Standard Gamma Sources}

To measure the counting efficiency of the detector,reference sources that have similar chemical composition, concentration, geometry and counting configuration as the studied samples. In the present study, International Atomic Energy Agency (IAEA) recommended reference samples were used. The reference samples are (1) IAEA/RGU-1: Uranium ore in silica powder containing radionuclides or components U, Th, K; (2) IAEA/RGTh-1: Thorium ore in silicapowder containing radionuclides or components Th, U, K; (3) IAEA/RGK-1: Extra pure Potassium sulphate containing radionuclides or components U, Th, K.. The cap of the container was tightly sealed with plastic tap to ensure its air tightness.

\subsection{Data Acquisition and Analysis of Gamma Spectra by Using Genie - 2000}

In the present research work, a HPGe Detector of CANBERRA(Model No. BE3820, Serial No. 09078305, Active area $3800 \mathrm{~mm}^{2}$, Thickness 20mm, Relative Efficiency of $38 \%$,Resolution of 1.9 $\mathrm{keV}(\mathrm{FWHM})$ for the peak of $1332 \mathrm{keV}$ of ${ }^{60} \mathrm{Co}$ )was used to carry out the whole measurements. Each of the reference sources was placed on the top of the detector within the shielding arrangement taking a counting time for 20,000 seconds. The most prominent gamma ray energy peaks were of $238.63 \mathrm{keV}$ (due to ${ }^{212} \mathrm{~Pb}$ ); $727.17 \mathrm{keV}$ (due to ${ }^{212} \mathrm{Bi}$ ); $241.98 \mathrm{keV}, 295.21 \mathrm{keV \&} 351.92 \mathrm{keV}$ (due to ${ }^{214} \mathrm{~Pb}$ ); $338.40 \mathrm{keV}$, $911.07 \& 969.11 \mathrm{keV}$ (due to ${ }^{228} \mathrm{Ac}$ ); $510.57 \mathrm{keV}, 583.19 \mathrm{keV} \& 2614.53 \mathrm{keV}$ (due to ${ }^{208} \mathrm{Tl}$ ); $609.31 \mathrm{keV}$, $1120.29 \mathrm{keV} \& 1764.49 \mathrm{keV}$ (due to ${ }^{214} \mathrm{Bi}$ ); $1460.75 \mathrm{keV}$ (due to ${ }^{40} \mathrm{~K}$ ) and $661.66 \mathrm{keV}$ (due to ${ }^{137} \mathrm{Cs}$ ). The gamma ray emitting radionuclides were identified by $\gamma$-ray spectral analysis. The peak area of each $\gamma$ energy point was determined by using software genie-2000.

\subsection{Sample Spectrum}

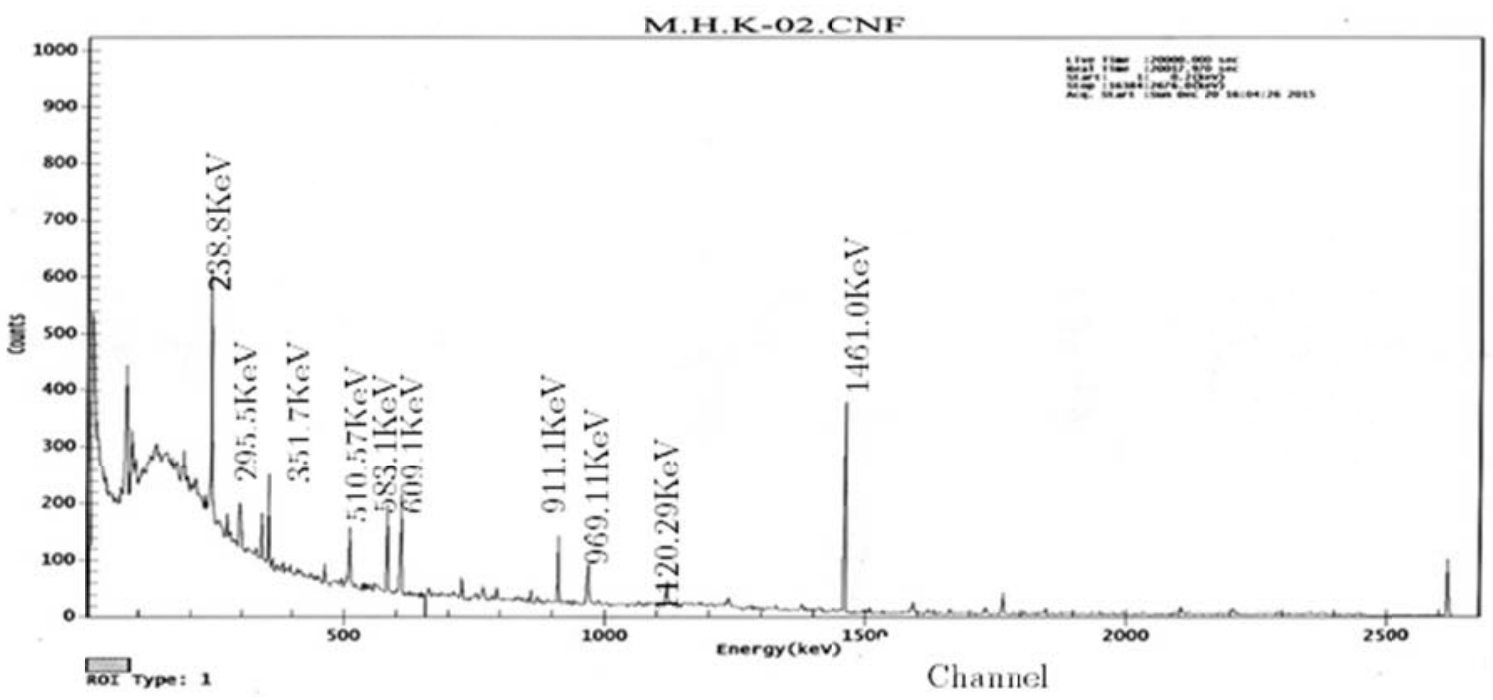

Figure 2: Counting gamma spectrum of the sample MHK-02 (Sedi-02)

\subsection{Efficiency Calibration Curve}

The counting efficiency of the (HPGe) detector was calculated by using the following formula: 


$$
\begin{gathered}
\% \text { Efficiency }=\frac{C P S \times 100}{\text { Activity } \times \text { Intensity }} \\
\text { or, } \varepsilon_{f}(\%)=\frac{C P S \times 100}{A_{C} \times I_{\gamma}}
\end{gathered}
$$

where, CPS $=$ Net count per second (i.e, Gross Counts- Background Counts)

Activity, $\mathrm{A}_{\mathrm{C}}=$ Standard source activity for the respective energy peak.

Intensity, $I_{\gamma}=$ Intensities of gamma energies.

Thus, from the measured count rates and known activities, the counting efficiencies at various gamma energy points for the corresponding source were calculated by the above equation.

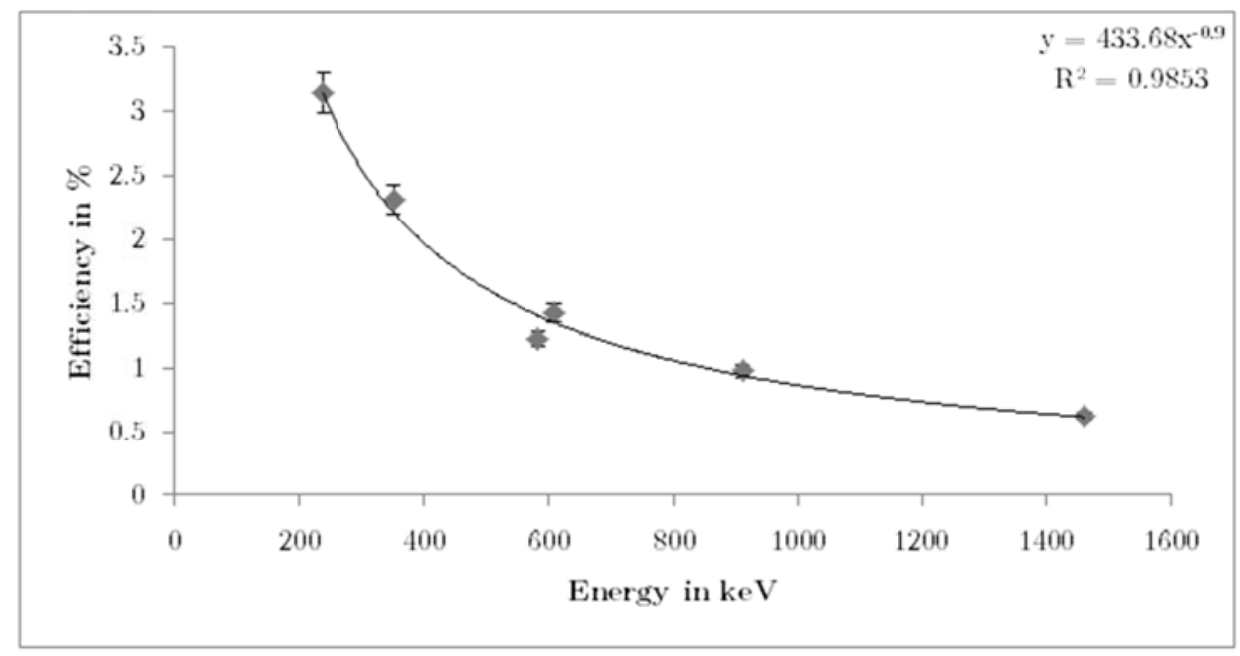

Figure 3: Counting efficiency curve of the (HPGe) Detector (For standard sample)

\subsection{Measurement of Radionuclides and Activity Concentration Calculation}

The samples after pretreatment, preparation and packing in the air tight sealed containers were stored for 4 weeks to reach secular equilibrium between the ${ }^{238} \mathrm{U}$ and ${ }^{232} \mathrm{Th}$ series and their respective progeny before their measurements ${ }^{(4,5,6)}$. It is assumed that ${ }^{222} \mathrm{Rn}$ and ${ }^{220} \mathrm{Rn}$ could not escape from the sealed containers from thin closure. The gamma ray activities of the Sediment and other's Biota samples were determined by the same calibrated detector coupled with Digital Spectrum Analyzer-1000 (DSA-1000). The most prominent gamma ray energies of ${ }^{212} \mathrm{~Pb}(238.63 \mathrm{keV}),{ }^{208} \mathrm{Tl}(583.19 \mathrm{keV})$ and ${ }^{228} \mathrm{Ac}(911.07 \mathrm{keV})$ and energies of ${ }^{214} \mathrm{~Pb}(351.92 \mathrm{keV}) \&{ }^{214} \mathrm{Bi}(609.31 \mathrm{keV})$ were used to determine the activity concentration of ${ }^{232} \mathrm{Th}$ and ${ }^{238} \mathrm{U}$ respectively. The ${ }^{40} \mathrm{~K}$ and ${ }^{137} \mathrm{Cs}$ radionuclides were measured from their respective $\gamma$-ray energies $1460.75 \mathrm{keV}$ and $661.66 \mathrm{keV}$, respectively ${ }^{(7,8,9,10)}$.

Before calculating the net counts, region of interest (ROI) was taken for every sample from the spectrum. In data analysis, the net count of the sample was brought about by subtracting a linear background distribution of the pulse height spectra from the corresponding peak energy area. Activities of the natural radionuclides presented in the sediment and other's biota samples were calculated by using the following formula ${ }^{(9)}$ :

$$
\text { Activity }=\frac{C P S \times 100 \times 1000}{\varepsilon_{f}(\%) \times I_{\gamma} \times w_{s}(g m)}
$$

where, CPS $=$ Net counts per second (i.e., CPS for sample - CPS for background)

$\varepsilon_{f}=$ Counting gamma energy efficiency of the detector.

$I_{\gamma}=$ Intensity of the gamma ray.

$\mathrm{W}_{\mathrm{s}}=$ Weight of the sample.

The error of the measurements was expressed in terms of standard deviation of $1 \sigma$ level. 


\subsection{Calculation of Radiological Hazard Parameters}

The outdoor absorbed dose rate in air at $1 \mathrm{~m}$ above the ground surface (in nGy.h $\mathrm{h}^{-1}$ ) using the conversion factors given in the UNSCEAR 2000 report $^{(12)}$ is

$$
D_{\text {outdoor }}=\left(0.427 C_{R a}+0.66 C_{T h}+0.0432 C_{K}\right)
$$

where, $\mathrm{C}_{\mathrm{Ra}}, \mathrm{C}_{\mathrm{Th}}$ and $\mathrm{C}_{\mathrm{K}}$ are average activity concentrations of ${ }^{226} \mathrm{Ra},{ }^{232} \mathrm{Th}$, and ${ }^{40} \mathrm{~K}$ respectively in sediment samples.

The indoor absorbed dose rate is 1.2 times higher than the outdoor dose given by(13)

$$
D_{\text {indoor }}=D_{\text {outdoor }} \times 1.2\left(n G y h^{-1}\right)
$$

The annual effective dose equivalent Deff from outdoor terrestrial gamma radiation is (14)

$$
D_{\text {eff }}=D_{\text {outdoor }}\left(n G y h^{-1}\right) \times 0.7\left(S v \cdot G y^{-1}\right) \times 8,760\left(h y^{-1}\right) \times 0.2
$$

where 0.2 is the outdoor occupancy factor and $0.7 \mathrm{~Sv}_{\mathrm{Gy}}{ }^{-1}$ is the quotient of effective dose equivalent rate to absorbed dose rate in air.

For indoor radiation exposure, the annual effective dose equivalent was calculated by using an occupancy factor of $0.8(14)$ as:

$$
D_{\text {eff }}=D_{\text {indoor }}\left(n G y h^{-1}\right) \times 0.7\left(S v \cdot G y^{-1}\right) \times 8,760\left(h y^{-1}\right) \times 0.8
$$

The total annual effective dose equivalent from terrestrial radiation is the sum of outdoor and indoor annual effective dose equivalent.

The external radiation hazard, Hext and internal radiation hazard, Hint are calculated as follows:

$$
\begin{aligned}
H_{\text {ext. }} & =\frac{A_{R a}}{370}+\frac{A_{T h}}{259}+\frac{A_{k}}{4810} \\
H_{\text {int }} & =\frac{A_{R a}}{185}+\frac{A_{T h}}{259}+\frac{A_{k}}{4810}
\end{aligned}
$$

where the numerical quantities of equations (5) and (6) are in units of $B q \cdot \mathrm{kg}^{-1}$ and $\mathrm{A}_{\mathrm{Ra}}, \mathrm{A}_{\mathrm{Th}}$ and $\mathrm{A}_{\mathrm{K}}$ are the activity concentration of ${ }^{226} \mathrm{Ra},{ }^{232} \mathrm{Th}$ and ${ }^{40} \mathrm{~K}$ respectively.

The formulas for calculating the radium equivalent activity (15), Raeq and the representative level index $(14,15,16), \mathrm{I} \gamma \mathrm{r}$ in the present research are as follows:

$$
\begin{gathered}
R a_{e q}=A_{R a}+1.43 A_{T h}+0.077 A_{k} \\
I_{\gamma r}=\left(\frac{C_{R a}}{150}+\frac{C_{T h}}{100}+\frac{C_{k}}{1500}\right)
\end{gathered}
$$

where, $A_{R a}, A_{T h}$ and $A_{K}$ in equation (7) and $C_{R a}, C_{T h}$ and $C_{K}$ in equation (8) are activity concentrations of ${ }^{226} \mathrm{Ra},{ }^{232} \mathrm{Th}$, and ${ }^{40} \mathrm{~K}$, respectively in sediment samples.

\section{$3 \quad$ Results and Discussion}

The concentrations for the corresponding gamma emitting radionuclides of all samples, collected from the St. Martin's island, Chittagong, Bangladesh were measured by using the High Purity Germanium detector. In the present study, the activity of ${ }^{238} \mathrm{U},{ }^{232} \mathrm{Th},{ }^{40} \mathrm{~K}$ and ${ }^{137} \mathrm{Cs}$ of all samples were measured within counting error of $1 \sigma$ level. The activity concentrations for three different types of samples are shown below:

\subsection{Activity Concentrations and Radiological Hazard Parameters of all Samples}

1. The activity concentrations of radionuclides of all samples have been shown in table 1 and the graphical representation for the radionuclides have been shown in Figure 4.

2. The radiological hazard parameters of all samples have been shown in Table 2. 
Table 1. The activity concentrations of the radionuclides, ${ }^{238} \mathrm{U},{ }^{232} \mathrm{Th},{ }^{40} \mathrm{~K}$ and of all samples.

\begin{tabular}{c|c|c|c|c}
\hline Sample Type & Sample id & ${ }^{238} \mathbf{U}$ & ${ }^{232} \mathbf{T h}$ & ${ }^{40} \mathbf{K}$ \\
\hline & sedi-1 & $15.93 \pm 2.1$ & $25.09 \pm 2.72$ & $341.77 \pm 47.2$ \\
\hline Sediment & sedi-2 & $25 \pm 2.17$ & $31.85 \pm 2.77$ & $358.32 \pm 47.1$ \\
\hline & sedi-3 & $20.29 \pm 2.25$ & $28.12 \pm 2.89$ & $498.34 \pm 53.3$ \\
\hline & sedi-4 & $7.75 \pm 2.04$ & $15.77+0.83$ & $640.84 \pm 56.23$ \\
\hline & Mean & $17.243 \pm 2.14$ & $25.207 \pm 2.302$ & $460.802 \pm 50.957$ \\
\hline & Coral f-1 & $13.09 \pm 14.04$ & $12.64 \pm 17.44$ & $464.74 \pm 305.61$ \\
\hline & Tak chandaf-2 & $8.63 \pm 19.19$ & $8.47 \pm 9.58$ & $265.1 \pm 417.08$ \\
\hline Fish & Mean & $\mathbf{1 0 . 8 6} \pm \mathbf{1 6 . 6 1 5}$ & $10.555 \pm 13.51$ & $364.92 \pm 361.345$ \\
\hline & Coral -1 & $\mathbf{1 3 . 0 6} \pm \mathbf{2 . 1}$ & $16.57 \pm 2.65$ & $84.96 \pm 43.29$ \\
\hline
\end{tabular}

\subsection{Activity Concentrations of 238U, 232Th and 40K for All Samples with the World} Values

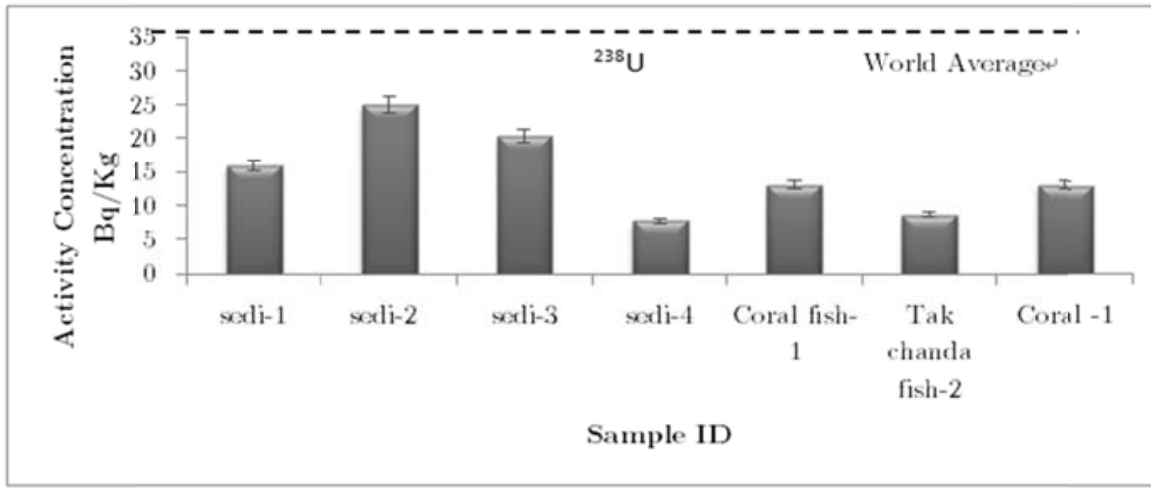

(a)

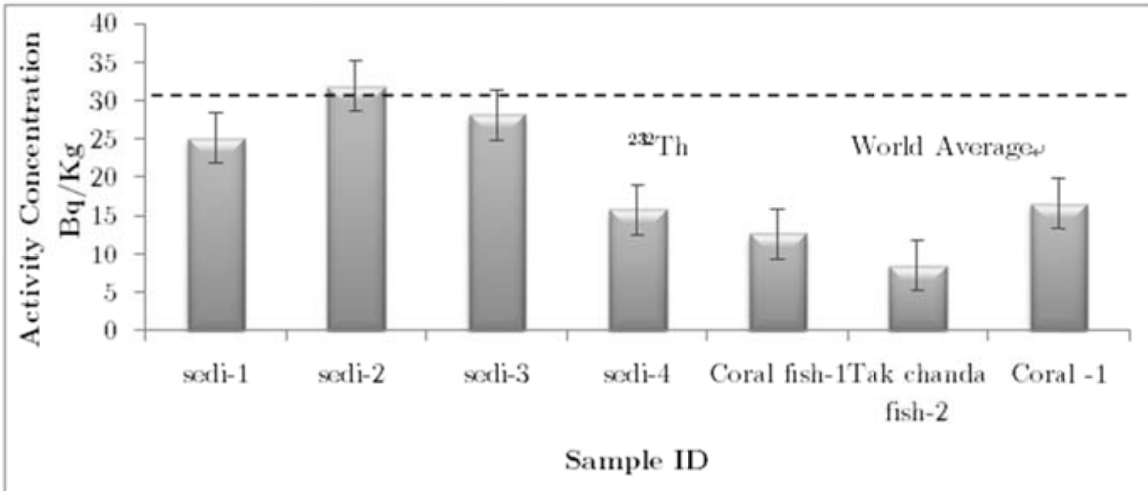

(b)

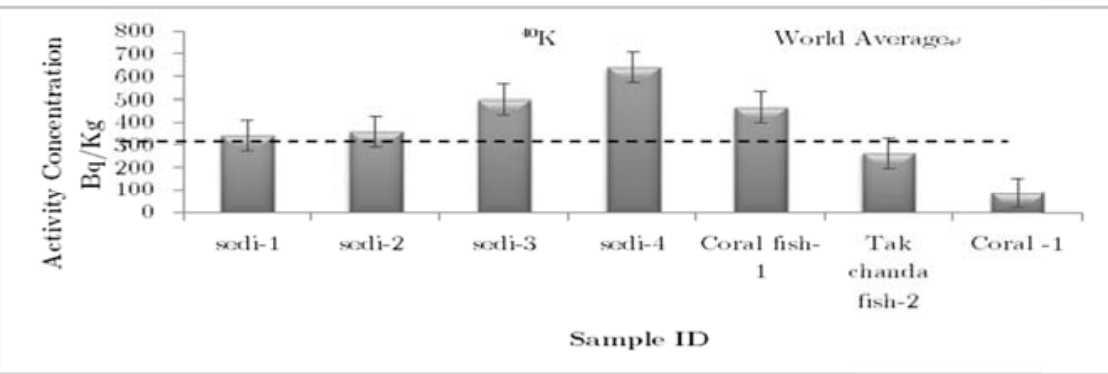

(c)

Figure 4: Comparison of the activity concentrations for all samples- (a) for ${ }^{238} \mathrm{U}$ (b) for ${ }^{232} \mathrm{Th}$ (c) for ${ }^{40} \mathrm{~K}$. 


\subsection{The Activity Concentration of 238U, 232Th and 40K for All Samples}

Activity of ${ }^{238} \mathbf{U}$ : The activity concentrations of ${ }^{238} \mathrm{U}$ of the sediment samples have been found in the range of $7.754 \pm 2.044$ to $25.005 \pm 2.176 \mathrm{~Bq} / \mathrm{kg}$ with an average value of $17.243 \pm 2.14 \mathrm{~Bq} / \mathrm{kg}$. The values of fish have been found in the range $8.639 \pm 19.19$ to $13.094 \pm 14.036$, an average value of $10.86 \pm 16.615$ $\mathrm{Bq} / \mathrm{kg}$. The value of coral is $13.06 \pm 2.1$; whereas the world average value is $35 \mathrm{~Bq} / \mathrm{kg}$. So, no activity concentration value is found above the world average value except coral.

Activity of ${ }^{232} \mathbf{T h}$ : The activity concentrations of ${ }^{232} \mathbf{T h}$ of the sediment samples have been in the range of $15.769 \pm 0.827$ to $31.852 \pm 2.773 \mathrm{~Bq} / \mathrm{kg}$ with an average of $25.207 \pm 2.302 \mathrm{~Bq} / \mathrm{kg}$. The values of fish have been found in the range of $8.471 \pm 9.58$ to $12.641 \pm 17.44 \mathrm{~Bq} / \mathrm{kg}$; an average value of is $10.555 \pm 13.515 \mathrm{~Bq} / \mathrm{kg}$. The value of coral is $16.57 \pm 2.65$. Whereas the world average value is $30 \mathrm{~Bq} / \mathrm{kg}$. The average activity concentration value is found below the world average value.

Activity of ${ }^{40} \mathbf{K}$ : The activity concentrations of ${ }^{40} \mathbf{K}$ of the sediment samples have been in the range of341.769 \pm 47.2006 to $640.841 \pm 56.237 \mathrm{~Bq} / \mathrm{kg}$ with an average of $460.802 \pm 50.957 \mathrm{~Bq} / \mathrm{kg}$. The values of fish have been found in the range $265.1 \pm 417.08$ to $464.742 \pm 305.61 \mathrm{~Bq} / \mathrm{kg}$ with an average of $364.92 \pm 361.345 \mathrm{~Bq} / \mathrm{kg}$. The value of coral is $84.96 \pm 43.29$; whereas the world average value is $400 \mathrm{~Bq} / \mathrm{kg}$ which shows that the average sediment value is higher than the world average value. For the case of fish samples the observed peak was distorted due to low sample weight and the short counting time.

\subsection{Calculation of Radiation Hazard Parameters:}

The radiological hazard parameters for all samples are shown in Table (2)

Table 2. The Comparison of the radiological hazard parameters among all type of samples.

\begin{tabular}{|c|c|c|c|c|c|c|c|}
\hline $\begin{array}{l}\text { Sample } \\
\text { ID }\end{array}$ & $\begin{array}{l}\text { Outdoor } \\
\text { absorbed Dose } \\
\text { rate in } \mathrm{nGy} \cdot \mathrm{h}^{-1}\end{array}$ & $\begin{array}{l}\text { Indoor } \\
\text { absorbed dose } \\
\text { rate in } \mathrm{nGy} \cdot \mathrm{h}^{-1}\end{array}$ & $\begin{array}{l}\text { The external } \\
\text { Radiation } \\
\text { hazard, } H_{\text {ext }}\end{array}$ & $\begin{array}{l}\text { The internal } \\
\text { radiation } \\
\text { hazard, } \mathrm{H}_{\mathrm{int}}\end{array}$ & $\begin{array}{l}\text { The annual } \\
\text { Effective dose } \\
\text { equivalent, } \\
D_{\text {eff }}\left(\mu \mathrm{Svy}^{-1}\right) \\
\end{array}$ & \begin{tabular}{|l|} 
The \\
representative \\
level index, \\
I $\gamma \mathrm{r}$ \\
\end{tabular} & $\begin{array}{l}\text { The radium } \\
\text { activity, } \\
\text { Raeq, } \\
\left(\mathrm{Bq} \cdot \mathrm{Kg}^{-1}\right)\end{array}$ \\
\hline Sedi-01 & $38.124 \pm 2.839$ & $45.748 \pm 3.406$ & $0.210+0.015$ & $0.254 \pm 0.018$ & $46.755 \pm 3.481$ & $0.584 \pm 0.043$ & $78.124 \pm 5.72$ \\
\hline Sedi-02 & $47.175 \pm 2.890$ & $56.61 \pm 3.468$ & $0.265+0.016$ & $0.332 \pm 0.018$ & $57.855 \pm 3.54$ & $0.724 \pm 0.044$ & $98.136 \pm 5.79$ \\
\hline Sedi-03 & $48.751 \pm 3.144$ & $58.5012 \pm 3.772$ & $0.267+0.016$ & $0.321 \pm 0.019$ & $59.788 \pm 3.85$ & $0.748 \pm 0.048$ & $98.873 \pm 6.24$ \\
\hline Sedi-04 & $41.401 \pm 2.638$ & $49.681 \pm 3.165$ & $0.215+0.0132$ & $0.236 \pm 0.016$ & $50.774 \pm 3.235$ & $0.636 \pm 0.040$ & $79.645 \pm 4.93$ \\
\hline Mean & $43.863 \pm 2.877$ & $52.636 \pm 3.452$ & $0.239+0.015$ & $0.286 \pm 0.018$ & $53.793 \pm 3.526$ & $0.673 \pm 0.043$ & $88.696 \pm 5.672$ \\
\hline $\begin{array}{l}\text { Coral fish- } \\
01\end{array}$ & $34.008 \pm 18.512$ & $40.809 \pm 22.214$ & $0.180+0.099$ & $0.216 \pm 0.119$ & $41.707 \pm 22.703$ & $0.523 \pm 0.284$ & $66.950 \pm 37.05$ \\
\hline $\begin{array}{l}\text { TakChanda } \\
\text { fish-02 }\end{array}$ & $20.727 \pm 20.7$ & $24.872 \pm 24.84$ & $0.112+0.107$ & $0.134 \pm 0.140$ & $25.419 \pm 25.39$ & $0.318 \pm .320$ & $41.154 \pm 39.84$ \\
\hline Mean & $27.368 \pm 19.606$ & $32.841 \pm 23.527$ & $0.146+0.103$ & $0.175 \pm 0.129$ & $33.563 \pm 24.046$ & $0.421 \pm 0.302$ & $54.052 \pm 38.446$ \\
\hline Coral-01 & $20.183 \pm 7.360$ & $24.219 \pm 8.832$ & $0.117+0.0147$ & $0.152 \pm 0.017$ & $24.752 \pm 9.02$ & $0.309 \pm 0.041$ & $43.297 \pm 5.47$ \\
\hline $\begin{array}{l}\text { World } \\
\text { Average }\end{array}$ & 60 & 72 & 1 & 1 & 80 & 0.66 & 370 \\
\hline
\end{tabular}




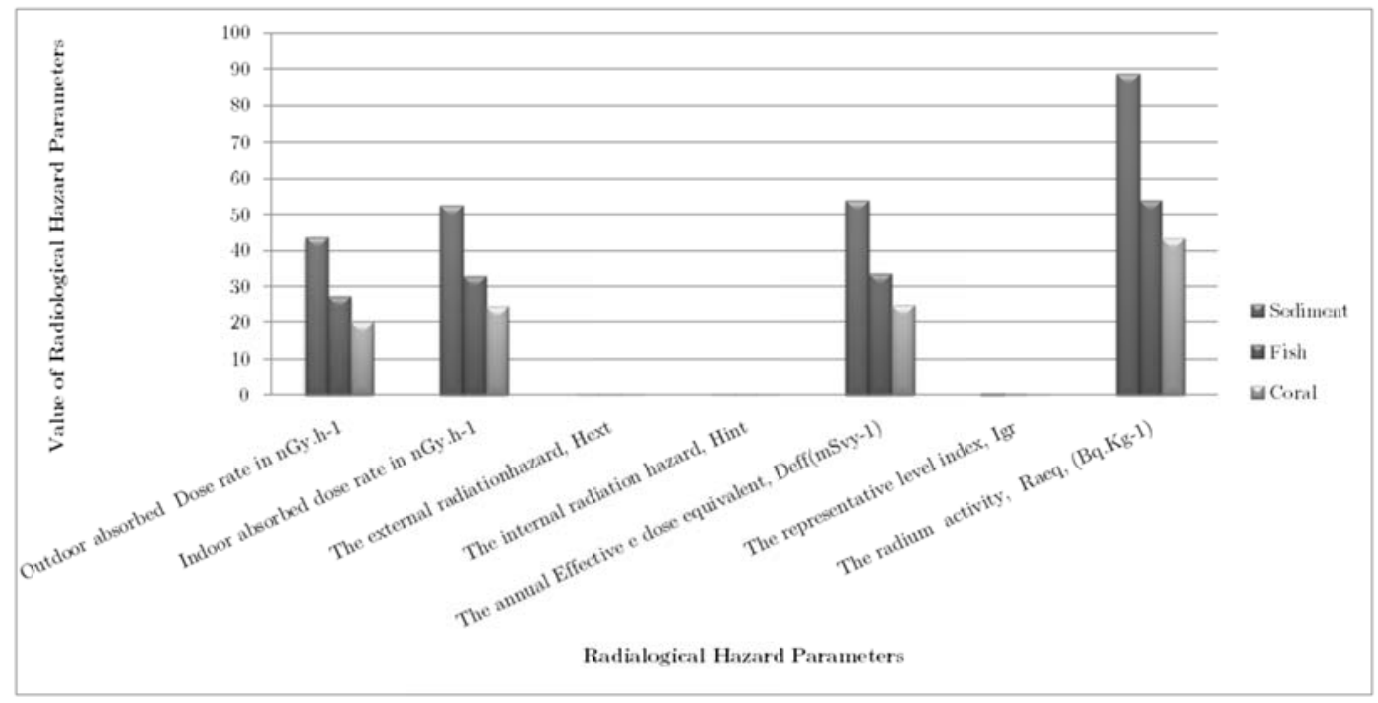

Figure 5: The Comparison of the radiological hazard parameters among all type of samples.

\subsection{The Radiological Hazard Parameters for All Samples}

A comparison of radiological hazard parameters for all samples has been shown in Table 2 and the graphical representations in Figure 5, respectively.

\subsubsection{The Outdoor Absorbed Dose Rate:}

The outdoor absorbed dose rate in air at $1 \mathrm{~m}$ above from the ground surface in the sediment samples have been found in the range of $38.124 \pm 2.839 \mathrm{nGy} \cdot \mathrm{h}^{-1}$ to $48.751 \pm 3.144 \mathrm{nGy} \cdot \mathrm{h}^{-1}$ with the mean value of $43.863 \pm 2.877 \mathrm{nGy} \cdot \mathrm{h}^{-1}$. The values of fish have been found between $20.727 \pm 20.7$ and $34.008 \pm 18.512$; an average value of $27.368 \pm 19.606 \mathrm{nGy} \cdot \mathrm{h}^{-1}$. The value of coral is $20.183 \pm 7.360$; whereas the world average value is $60 \mathrm{nGy} \cdot \mathrm{h}^{-1}$. So, no outdoor absorbed dose rate's value is found above the world average.

\subsubsection{The Indoor Absorbed Dose Rate:}

The indoor absorbed dose rate in air for the sediment samples have been found in the range of $45.748 \pm 3.4068$ nGy.h-1 to $58.5012 \pm 3.772$ nGy.h-1 with the mean value of $52.636 \pm 3.452$ nGy.h- 1 . The values of fish have been found in the range $24.872 \pm 24.84$ to $40.809 \pm 22.214$ with an average value of $32.84 \pm 23.527$ nGy.h- 1 . The value of coral is $24.219 \pm 8.832$; and the world average value is $72 \mathrm{nGy} . \mathrm{h}-$ 1(17). So, no indoor absorbed dose rate was found above the world average.

\subsubsection{The External Radiation Hazard,(Hext):}

The external radiation hazard values for the sediment samples have been found in the range of $0.210 \pm 0.015$ to $0.267 \pm 0.016$ with the mean value $0.239 \pm 0.015$. The values of fish have been found in the range $0.112 \pm 0.107$ to $0.180 \pm 0.099$ with mean value of $0.146 \pm 0.103$. The value of coral is $0.117 \pm 0.0147$; whereas the world average value is 1(19).So the external radiation hazard's value is less than the world average. Therefore, the St. Martin Island is safe for the tourists and the inhabitants nearby.

\subsubsection{The Internal Radiation Hazard,(Hint):}

The internal radiation hazard for the sediment samples have been found in the range of $0.236 \pm 0.016$ to $0.332 \pm 0.018$ with the mean value being $0.286 \pm 0.018$. The values of fish have been found in the range from $0.134 \pm 0.140$ to $0.216 \pm 0.119$; an average value of $0.175 \pm 0.129$. The value of coral is $0.152 \pm 0.017$; whereas the world standard value is 1(19).So The internal radiation hazard value is less than the world average.

\subsubsection{The Annual Effective Dose Equivalent (Deff):}

The annual effective dose equivalent for the sediment samples has been found in the range of $46.755 \pm 3.481$ to $59.788 \pm 3.85$ with the mean value being $53.793 \pm 3.526$. The values of fish have been found in the range of $25.419 \pm 25.39$ to $41.707 \pm 22.703$ with an average value of $33.563 \pm 24.046$. The value of coral is $24.752 \pm 9.02$; whereas the world average value is $80 \mu S v y-1^{(19)}$. So, the annual effective dose equivalent value is less than the world average value. 


\subsubsection{The Representative Level Index (I $\gamma$ r):}

The representative level index for the sediment samples has been found in the range of $0.584 \pm 0.043$ to $0.748 \pm 0.048$ with the mean value being $0.673 \pm 0.0437$. The values of fish have been found in the range $0.318 \pm 0.320$ to $0.523 \pm 0.284$; an average value of $0.421 \pm 0.302$. The value of coral is $0.309 \pm 0.041$; whereas the world standard value is $0.66(19)$. So, the representative level index value for sediments is within the world average value.

\subsubsection{The Radium Equivalent Activity,(Raeq):}

The radium equivalent activity for the sediment samples has been found in the range of $78.124 \pm 5.72$ $\mathrm{Bq} / \mathrm{kg}$ to $98.873 \pm 6.24 \mathrm{~Bq} / \mathrm{kg}$ with the mean value being $88.695 \pm 5.672 \mathrm{~Bq} / \mathrm{kg}$. The values of fish have been found in the range $41.154 \pm 39.84 \mathrm{~Bq} / \mathrm{kg}$ to $66.950 \pm 37.05 \mathrm{~Bq} / \mathrm{kg}$. The average value of fish is $54.052 \pm 38.446 \mathrm{~Bq} / \mathrm{kg}$. The value of coral is $43.29 \pm 5.466 \mathrm{~Bq} / \mathrm{kg}$; whereas the world standard value is 370 $\mathrm{Bq} / \mathrm{kg}$ (19). So, the radium equivalent activity value is less than the world average. In this graph, the values of the external radiation hazard,(Hext), the internal radiation hazard,(Hint) \& the representative level index $(\mathrm{I} \gamma \mathrm{r})$ were very small and that is why it was not shown very clearly in the representation.

\section{Conclusion}

The detection of radionuclides, their activity concentrations and radiological hazard parameters of three different kinds of total seven (four sediment, two fish and one coral) samples collected from St. Martin's Island. Chittagong, Bangladesh were determined as a part of assessment of the radiological impact of St. Martin's island on the inhabitants and the tourists. The detection of natural radionuclides of ${ }^{238} \mathrm{U},{ }^{232} \mathrm{Th}$, ${ }^{40} \mathrm{~K}$ and ${ }^{137} \mathrm{Cs}$ and their activity concentrations were determined by using a calibrated High purity Germanium Detector (HPGe). There is no artificial radionuclide found in this study. The activity concentrations and radiological hazard parameters for all samples were determined individually. The activity concentration values for most of the samples were lower and for a few were higher than the world average values. The radiological hazard parameters of these samples were found within the acceptable limit set by the ICRP report which shows that there is no radiation hazard risk for the inhabitants and the tourists. Therefore, we can say that this island is safe for both inhabitants and tourists.

\section{References}

1. Wikipedia, https://en.wikipedia.org/wiki/St._Martin's_Island.

2. Banglapedia, http://en.banglapedia.org/index.php?title=St_Martin's_Island.

3. M.I. CHOWDHURY et al (2004): "Environmental Radioactivity of the St. Martin's Island of Bangladesh", J. of Radioprotection Vol. 39, No. 1, PP (13 -21). DOI:10.1051/radiopro:2003018.

4. UNSCEAR,United Nations Scientific Committee on the Effects of Atomic Radiation, Exposure from Natural Sources of Radiation, Report to the General Assembly, with annexes; United Nations, New York (1988).

5. A. Malanca, V. Pessina, G. Dallara, C.N. Luce and L. Gaidolft(1995): "Natural Radioactivity in Building Materials from the Brazilian State of Espirito Santo", J. of Applied Radiation \& Isotopes, U.K., Vol. 46, No. 12, pp. 1387-1392 (1995)

6. N.M. Ibrahiem, S.M. Shawky and H.A.Amer (1995):"Radioactivity levels in Lake Nasser sediment", J. Of Applied Radiation \& Isotopes, Vol. 46, No. 5, pp. 297-299.

7. N. M. Ibrahiem and M. Pimpl (1994): "Uranium concentrations in sediments of the Suez Canal", J. of Applied Radiation \& Isotopes. Vol. 45 No-9, pp. 919-92 (1994).

8. Faiz M. Khan, The Physics of Radiation Therapy, second edition, Lippincott Williams \& Wilkins (1994).

9. ICRP (1983): "Radionuclide Transformations, Publication of International Commission on Radiological Protection", Publication No.-38, Vol. 11-13 (1983).

10.J. P. Boliver, R. Garcia-Tenoria and M. Garcia-Leon (1995): "Fluxes and distribution of Natural Radionuclides in the Production and Use of Fertilizers", J .ofApplied Radiation Isotopes. U.K., Vol. 46, No. 7, pp. 717-718.

11.T. Jabbar, K. Khan, M. S. Subhani, P. Akhter and A. Jabbar (2008): "Environmental Gamma Radiation Measurement in District Swat-Pakistan", J. of Radiation Protection Dosimetry, Vol. 132, No. 1, pp. 88-93. 
12.UNSCEAR (2000): "United Nations Scientific Committee on The Effects Of Atomic Radiation", Report to the General Assembly with Scientific Annexes, Vol. 1 \& 2, United Nations, New York.

13.B. E. Akhtyrtsev, A. B. Akhtyrtsev, and L. A. Yablonskikh (1999): "Content and vertical distribution of heavy metals and radionuclide's in hydromorphic soils of the forest-steppe zone of the Russian Plain", J. of Eurasian Soil Science, Vol. 32, No. 4, pp. 394-403.

14.N. H. Cutshall, I. L. Larsen, and C. R. Olsen (1983): "Direct Analysis of 210Pb in Sediment Samples Selfabsorption Corrections", J. of Nuclear Instruments Methods, Vol. 69, pp. 309-312.

15.J. Beretka, and P. J. Mathew (1985): "Natural Radioactivity in Australian Building Materials, Industrial Waste and By-Products", J. of Health Physics, Vol. 48, pp. 87-95 .

16.NEA/OECD Nuclear Energy Agency (1979): "Exposure to Radiation from Natural Radioactivity in Building Materials",Report by NEA Group of Experts (Paris: OECD) .

17.Xinwei Lu, and Xiaolan Zhang (2008): "Natural Radioactivity Measurements in Rock Samples of Cuihua Mountain National Geological Park-China”,J. of Radiation Protection Dosimetry, Vol. 128, No. 1, pp. 77-82 .

18.B. N. Hamid, M. I. Chowdhury, M. N. Alam and M. N. Islam (2002): "Study of Natural Radionuclide Concentrations in an Area of Elevated Radiation Background in the Northern Districts of Bangladesh",J. of Radiation Protection Dosimetry Vol. 98, No. 2, pp. 227 - 230

19.N. M. Ibrahiem and M. Pimpl (1994): "Uranium concentrations in sediments of the Suez Canal", J. of Applied Radiation \& Isotopes. Vol. 45 No-9, pp. 919-92. 